\title{
Dutch politicians' coping with terrorist threat
}

\author{
Mirjam J. Nijdam, Berthold P. R. Gersons and Miranda Olff
}

\section{Summary}

The psychosocial effects of terrorist threat and close protection have never been studied systematically in politica leaders. We conducted a study among 12 Dutch politicians and their partners who were living under terrorist threat and close protection in the aftermath of two political murders. Interviews revealed that their coping with the situation varied and consisted of emotion-focused, defensive, palliative and instrumental coping strategies. Symptoms of post-traumatic stress disorder occurred in some individuals, and tendencies to express milder or stronger opinions on sensitive issues were reported. Psychosocial knowledge can be useful in helping to cope with the situation in the best possible way.

\section{Declaration of interest}

None.
Two political murders in The Netherlands, in 2002 and 2004, affected the political climate dramatically. A safe and tolerant country where ministers were seen cycling to work suddenly turned into a country in which terrorist groups threatened to kill politicians with outspoken non-conformist views. Leading politicians are, by the nature of their profession, highly competent and resilient people. Nevertheless, death threats can have a psychosocial impact, especially if such threats are focused on the politician's loved ones. ${ }^{1}$ The psychosocial effects of terrorist threat and subsequent close protection on politicians have never been studied systematically. Our aim was to gain insight into these processes and to facilitate a more systematic approach to the support of threatened politicians and their families. In accordance with stress-coping theory, ${ }^{2,3}$ we hypothesised that coping strategies and responses to threats differ between individuals and over time. ${ }^{3}$ In line with terror management theory, ${ }^{4}$ we expected that reminders of the person's own mortality would reinforce their cultural values and world view. ${ }^{5}$ In a similar vein, death threats could influence the standpoints of society's leaders by confronting them with their own mortality.

\section{Method}

Twelve semi-structured interviews were conducted with threatened individuals and their partners by all authors. The threatened individuals were either politicians or held other major public positions protected by the Dutch National Coordinator for Counterterrorism. Some of them were still living under threat and close protection at the time of the interview, whereas others had been threatened and protected in the past. Most of them had received severe life threats from terrorists in the aftermath of the political murders and a few from organised crime groups. The National Coordinator for Counterterrorism approved the study design, and approached the respondents for the interviews. The interviews were conducted at secured offices or secured politicians' homes. Three other individuals were approached, but did not wish to participate. Data were collected from May 2006 until December 2007. The respondents provided oral informed consent for their participation in the study after complete description of the study procedure, and approved the relevant parts of the manuscript.

A semi-structured interview format was constructed by the authors based on three phases in the protection process: (1) the beginning phase, in which the person first hears about the threat and the protective measures that will be taken; (2) the middle phase, in which the threat and protection are at a relatively constant level for an extended period of time; and (3) the final phase, in which the protection is downgraded and ultimately terminated. This categorisation takes into account the time dimension in stress responses. ${ }^{6}$ Respondents were interviewed once; data from earlier phases were retrospective and for some the final phase was not addressed because protection was ongoing at that time. All applicable topics were addressed in all interviews. The interviews were transcribed and systematically sorted by all authors into emergent themes to ensure the validity of the findings. The analysis was aimed at describing the occurrence of coping strategies used by the politician and their partner, nature of the symptoms of the politician and their partner, causes and triggers for the symptoms, and consequences for professional practice. (The interview protocol is available from the authors upon request.)

Since the protection of individuals in a public position is by definition shrouded in confidentiality and secrecy, the authors were required to ensure confidentiality and to make it impossible to recognise the people involved. Therefore, exact numbers are not displayed and demographic characteristics of participants have been changed at random or omitted. As a result, any association that the reader could make with a specific person will be factually incorrect.

\section{Results}

The interviews revealed that politicians and their partners used various coping styles in order to regain control over the threatening situation. Some protected individuals entered into socially supportive relationships with the protectors: an emotion-focused coping strategy. Forming attachments helped them feel safer and more in control. Defensive reactions occurred when the protected individuals initially experienced the situation as very unreal, and took a very dependent attitude towards the protectors. In some cases, alcohol consumption was increased in an attempt to reduce the tension elicited by the threats, which can be interpreted as a palliative coping strategy. An instrumental coping strategy occurred when protected individuals elevated themselves above the protection officers in order to regain control. Defensive reactions were more likely to occur in the beginning phase when the person was informed about the threats, whereas instrumental and emotion-focused strategies were more frequently used in the middle phase.

All protected individuals, including partners, indicated that they had developed some symptoms during or after the threats and protection. Post-traumatic stress disorder symptoms occurred 
in some cases (for example, nightmares, hypervigilance, startle reactions, difficulty concentrating, and problems falling asleep). Furthermore, a depressed mood and panic symptoms were mentioned, as well as physical symptoms (e.g. tension, fatigue). The symptoms were most likely to occur in the beginning phase when being informed about the threats and in the downgrading phase when protection was diminished. In the middle phase, most participants experienced a certain degree of acclimatisation.

Several reactions emerged from the interviews regarding professional practice. In general, protected individuals did not want the threats to get the better of them. However, increased anxiety made some of them more cautious in expressing their opinions about sensitive issues. In the most extreme case, this led to the person resigning from their position when family members were also threatened. Conversely, their points of view were sometimes also strengthened by the threats. The presence of armed protection officers, although taken as a measure to increase safety, also elevated the subjective perception of threat in some cases. As a result, a tendency emerged to express slightly stronger opinions on sensitive issues.

\section{Discussion}

A situation of threat and protection happens to people who are in principle healthy, but experience difficulties with the disruptive effects of stress and traumatic stress to a greater or lesser extent. Based on the nature and severity of the symptoms reported, it is unlikely that the politicians in our study will develop a full psychiatric disorder. Therefore, terrorist threats and protection do not necessarily endanger professional functioning, but do have psychosocial effects that should be mitigated wherever possible.

The results from the interviews are in line with stress-coping theory and terror management theory; these approaches can be of use to mental health professionals in advising politicians, their partners, and other people in a situation of ongoing threat. For a resilient reaction, it is important that the person has a sense of control regarding the potentially traumatic situation. ${ }^{7}$ Active coping also prevents symptoms in the long term, ${ }^{8}$ whereas negative coping is less helpful. ${ }^{9,10}$ This study has resulted in a programme in which Dutch politicians under threat are advised by mental health professionals on healthy coping strategies and on how the threatening situation can influence political decision-making.

Limitations of this study include the absence of a control group, a small sample size and lack of quantitative data. Since this is the first attempt, to our knowledge, to systematically describe the sequelae of threat and close protection in politicians, future research with standardised measures is encouraged, preferably using an international framework.

Mirjam J. Nijdam, MSC, Berthold P. R. Gersons, MD, PhD, Miranda Olff, PhD, Centre for Psychological Trauma, Department of Psychiatry, Academic Medical Centre at the University of Amsterdam, Amsterdam, The Netherlands

Correspondence: Mirjam J. Nijdam, Centre for Psychological Trauma, Department of Psychiatry, Academic Medical Centre at the University of Amsterdam, Meibergdreef 5, 1105 AZ Amsterdam, The Netherlands. Email: m.j.nijdam@amc.uva.n

First received 22 Dec 2009, final revision 2 Jul 2010, accepted 22 Jul 2010

\section{Funding}

This study was funded by the Dutch National Coordinator for Counterterrorism.

\section{Acknowledgement}

We thank Wil Martens and Maaike de Vries for their contribution to the study.

\section{References}

1 Bovenkerk F. Bedreigingen in Nederland. [Threats in the Netherlands.] Uitgeverij Augustus, 2005.

2 Ursin H, Eriksen HR. The cognitive activation theory of stress. Psychoneuroendocrinology 2004; 29: 567-92.

3 Olff M, Langeland W, Gersons BPR. Effects of appraisal and coping on the neuroendocrine response to extreme stress. Neurosci Biobehav Rev 2005; 29: 457-67.

4 Greenberg J, Pyszczynski T, Solomon S. The causes and consequences of a need for self-esteem: a terror management theory. In Public Self and Private Self (ed RF Baumeister): 189-212. Springer-Verlag, 1986.

5 Hart J, Shaver PR, Goldenberg JL. Attachment, self-esteem, worldviews, and terror management: evidence for a tripartite security system. J Pers Soc Psychol 2005; 88: 999-1013.

6 Eriksen HR, Olff M, Murison R, Ursin H. The time dimension in stress responses: relevance for survival and health. Psychiatry Res 1999; 85: 39-50.

7 Hoge EA, Austin ED, Pollack MH. Resilience: research evidence and conceptual considerations for posttraumatic stress disorder. Depress Anxiety 2007; 24: 139-52.

8 Silver RC, Holman EA, McIntosh DN, Poulin M, Gil-Rivas V. Nationwide longitudinal study of psychological responses to September 11. JAMA 2002; 288: $1235-44$.

9 North CS, Nixon SJ, Shariat $\mathrm{S}$, Mallonee $\mathrm{S}$, McMillen JC, Spitznagel EL, et al. Psychiatric disorders among survivors of the Oklahoma City bombing. JAMA 1999; 282: 755-62.

10 Einav S, Shalev AY, Ofek H, Freedman S, Matot I, Weiniger CF. Differences in psychological effects in hospital doctors with and without post-traumatic stress disorder. Br J Psychiatry 2008; 193: 165-6. 